\title{
Evaluation of Clinical Efficacy of Metformin Therapy in Polycystic Ovary Syndrome
}

\author{
Chandran Jaganmohan 1,2, Mani Vannan ${ }^{1,3}$, Ashraf Ali', Parasuraman $\mathrm{S}^{4}$ \\ 'Department of Pharmacy, Sunrise University, Bagad Rajput, Alwar, Rajasthan 301030, INDIA. \\ 2Unit of Clinical Pharmacy \& Pharmacy Practice, Faculty of Pharmacy, AIMST University, Semiling, Bedong, 08100, MALAYSIA. \\ ${ }^{3}$ Department of Pharmaceutical Biotechnology, JKK Munirajah Inst of Health Sciences, College of Pharmacy, Gopichettipallayam, Tamil Nadu, INDIA. \\ ${ }^{4}$ Unit of Pharmacology, Faculty of Pharmacy, AIMST University, Semiling, Bedong, 08100, MALAYSIA.
}

\begin{abstract}
Objective: To evaluate the metformin efficacy in Polycystic Ovary Syndrome (PCOS), intent to regulate the menstrual cycle and achieving pregnancy rate (live birth, stillbirth) in infertile women with PCOS proportions experiencing spontaneous abortion and time of pregnancy and investigation of the neonatal out comes. Methods: The cross sectional observational study was conducted between January 2012 and December 2014. Totally 310 patients with PCOS in the age group of 18 to 35 enrolled in the study and 220 patients with PCOS were included in the study. Evaluation included the collection of laboratory data, efficacy assessment of hirsutism, acne in PCOS and pre and post therapy of metformin in abortion rate, malformation and live birth rates. Result: Totally 101 subjects had a symptoms of acne and 117 subjects were had symptoms of hirsutism. Metformin therapy significantly reduced incidence of acne and hirsutism. Metformin therapy also significantly increased the number of conceptions from 112 to 138 and reduced abortion and malformation rates. Conclusion: This study has shown a consistent efficacy of metformin in PCOS of patients and
\end{abstract}

improves the live birth rates. Thus, it demonstrates that the therapy of metformin was efficient and well tolerated, especially in teritoginicity and resumes the menstrual cyclicity and reduces the acne and hirsutism in PCOS patients.

Key words: Acne, Hirsutism, Metformin, Pregnancy, Polycystic Ovary Syndrome.

\section{Correspondence :}

Chandran Jaganmohan,

Sunrise University, Bagad Rajput, Alwar,

Rajasthan 301030, INDIA.

Phone no: +60 44298000 (Ext.: 1284)

Email: pharmjaganmohanc@gmail.com

DOI: 10.5530/jyp.2017.9.54

\section{INTRODUCTION}

Polycystic ovary syndrome (PCOS) is also known as sclerocystic ovarian disease, affects approximately 15 million women, which is about $5 \%$ to $10 \%$ of the female population in reproductive ages of $13-45$ years. ${ }^{1}$ As many as $20 \%$ of women with infertility problems have been diagnosed with PCOS. ${ }^{2}$ A complete underlying pathophysiology of PCOS is still unknown. The heterogeneity of PCOS has shown multiple pathophysiological mechanisms such as hyperandrogenism and/or hyperandrogenemia, oligo-ovulation, insulin resistance, adipose tissue dysfunction, obstetrical complications, infertility and mood and eating disorders. ${ }^{3}$

Clinical examination usually showed abundant cervical mucus, indicating the high estrogen levels. The diagnosis of PCOS may either be asymptomatic or present with symptom such as an hirsutism on moustache beard areas of face, breast and upper abdomen, acne, alopecia, excess body weight and obesity, acanthosis nigricans, impaired glucose tolerance, hypercholestremia, irregular menses and infertility. 4,5 The treatment usually depends upon the patient's intent to regulate the menstrual cycle and to provide prevalence care such as behaviour changes, regulating diet and increasing physical activities prior to the pharmacologic treatment. ${ }^{6,7}$ Development of insulin resistance due to hyperinsulinemia is one of the major cause of PCOS and it can be treated by administering anti-diabetic agents especially metformin. The underlying mechanism of metformin for the treatment on PCOS and metformin clinical effect on PCOS is not clear. Hence this present study was undertaken to evaluate the efficacy of metformin therapy in PCOS.

\section{MATERIALS AND METHODS}

The retrospective observational study was conducted between January 2012 and December 2014 in the department of Obstetrics and Gynecology $(\mathrm{O} \& \mathrm{G})$ in Vaatsalya Hospital, Mandya, Karnataka, India. This study was approved by the Internal Review Boards of Vaatsalya Hospital, Mandya, India, and this study was conducted according the declaration Helsinki. All the subjects data obtained from medical record department of Vaatsalya Hospital, Mandya.

Subjects either with oligomenorrhea, amenorrhea or with manifestation of hyperandrogenism like hirsutism, acne and bilateral polycystic ovaries on ultra sonography who are prescribed metformin $500 \mathrm{mg}$ twice or thrice daily or $1000 \mathrm{mg}$ twice daily were included in the study. Subjects consuming ovulation induction drug clomiphene citrate and oestrogenprogesterone contraceptive pills, undergoing laparoscopy surgery, bilateral tubal block, male factor infertility and suffering with diabetes mellitus were excluded from the study. Totally 310 patients with PCOS in the age group of 18 to 35 years were enrolled in the study and 220 patients with PCOS were included in the study and remaining was excluded from the study.

Maternal data includes demographics details, family history, past medical history, obstetrics history, transvaginal ultrasound report, laboratory investigations and current diagnosis were extracted from the medical record. Apart from that, this study also determines the safety and efficacy of metformin in achieving pregnancy rate (live birth, stillbirth) in infertile women with PCOS proportions experiencing spontaneous abortion and time of pregnancy and investigation of the neonatal out comes. 


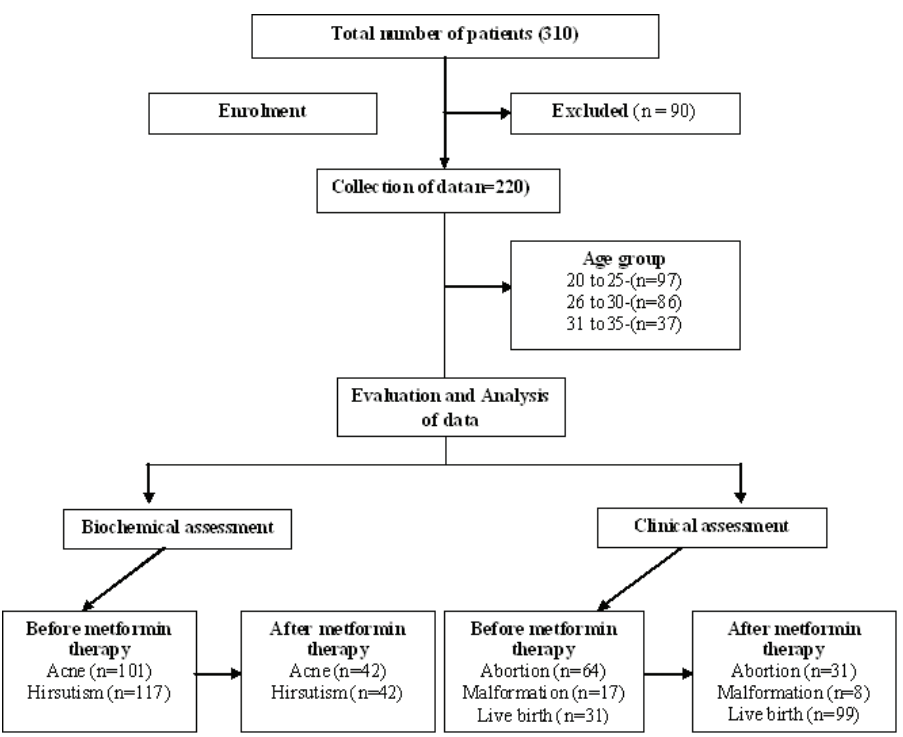

Figure 1: Study enrolment, assessment follow-up of subjects

The parameter to diagnose PCOS such as irregular menses, conception rate, malformations, abortion and number of pregnancy were measured and effect of metformin on PCOS also analysed. Data on malformations, abortion rate, live birth rates and menstrual pattern during metformin therapy was observed. Flow diagram of requirement, assessment and follow-up of participants are given in Figure 1.

\section{Statistical Analysis}

Descriptive statistics were used to summarize the baseline characteristics. The subjects were based on the duration of metformin therapy and Kruskal-Wallis test was used to determine the metformin effects on neonatal outcome for different period. The clinical profile outcome measures in a group were analysed using paired $t$-test. Effect of metformin treatment is measured by Pearson correlation. A $P$ value less than 0.05 were considered as significant.

\section{RESULTS}

Totally 310 females subjects were enrolled in the studyand 220 subjects were included in the study. The mean age of the study participants was $26.64 \pm 3.64$ years in that 97,86 and 37 subjects were at the age groups of 20-25, 26-30 and 31-35 years respectively Table 1 . Totally 101 subjects had a symptoms of acne and 117 subjects were had symptoms of hirsutism. Metformin therapy significantly reduced the incidence of acne and hirsutism. After metformin therapy the sign of acne and hirsutism reduced to 42 Table 2. Ferriman-Gallway score or any other standard procedure was not employed to measure hirsutism because of it is out of scope of current study which primarily aims at direct endpoints of conception. Prior to metformin therapy totally 41 subjects has regular menses and remaining subjects were had irregular menses. This was modified by metformin and number of participants with regular menses after metformin therapy were 138 subjects.

Before initiation of metformin therapy, 64 subjects out of total 220 subjects undergone first trimester spontaneous abortion and 17 subjects experienced teratogenicity a paltry, 31 subjects had normal live birth. Metformin therapy significantly increases the number of conceptions from 112 to 138 . Only 31 subjects were give normal birth before treatment and metformin significantly increase the conception rate, 99 subjects give a normal live birth of these PCOS subjects. Totally
Table 1: Baseline characteristics of the patients

\begin{tabular}{cc}
\hline Demographic details & Number (Mean \pm SD) \\
\hline Number of subjects enrolled & 310 \\
Number of subjects participated & 220 \\
Age (in years) & $26.73 \pm 4.98$ \\
$18-24$ & 97 \\
$25-30$ & 86 \\
$31-35$ & 37 \\
Weight (in kg) & $58.76 \pm 6.87$ \\
\hline
\end{tabular}

Table 2: Summary of metformin therapy outcome

\begin{tabular}{cccccc}
\hline \multirow{2}{*}{$\begin{array}{c}\text { Sing and } \\
\text { symptoms }\end{array}$} & Treatment & Number of & \multicolumn{3}{c}{ Age groups } \\
\cline { 4 - 6 } & & Subjects & 20-25 & $26-30$ & 31-35 \\
\hline \multirow{2}{*}{ Acne } & Before & 101 & 86 & 14 & 1 \\
& After & 42 & 41 & 1 & 0 \\
\multirow{2}{*}{ Hirsutism } & Before & 117 & 38 & 47 & 32 \\
& After & 42 & 14 & 13 & 15 \\
\hline
\end{tabular}

Table 3: Summary of clinical and biochemical data of study participants

\begin{tabular}{cc}
\hline Particulars & Number (Percentage) \\
\hline Obstetrics History & $112(50.90 \%)$ \\
No. of pregnancies & $31(32.00 \%)$ \\
No. of live birth & $64(66.00 \%)$ \\
No. of abortion & $17(2.00 \%)$ \\
Malformation & \\
Biochemical profile & $101(100.0 \%)$ \\
Acne before treatment & $42(41.58 \%)$ \\
Acne during/after treatment & $117(100.0 \%)$ \\
Hirsutism before treatment & $42(35.89 \%)$ \\
Hirsutism after treatment & \\
Clinical profile & $138(62.77 \%)$ \\
No of pregnancy & $99(72.0 \%)$ \\
Live birth after treatment & $31(22.0 \%)$ \\
Abortion after treatment & $8(6.0 \%)$ \\
Malformation after treatment &
\end{tabular}

Table 4: Effect of metformin therapy in PCOS

\begin{tabular}{ccc}
\hline & $\begin{array}{c}\text { Before metformin } \\
\text { treatment (in number) }\end{array}$ & $\begin{array}{c}\text { After metformintreatment } \\
\text { (in number) }\end{array}$ \\
\hline Abortion & 64 & 31 \\
Malformation & 17 & 8 \\
Live birth & 31 & 99 \\
\hline
\end{tabular}

61 subjects were received metformin full term, in that 50 subjects had live birth Table 3,4 .

When metformin was administered throughout pregnancy to women with the disorder, the rate of early pregnancy loss was decreased dramatically when compared with the results obtained before metformin therapy. 
Jaganmohan et al.,: Clinical efficacy of metformin therapy in polycystic ovary syndrome

\section{DISCUSSION}

Metformin therapy is markedly reduced the hirsutism, acne and improved conception rates. Metformin is a biguanide class of antidiabetic agents classified under pregnancy category B and this was used for the treatment of PCOS and gestational diabetes mellitus. ${ }^{8}$ Generally, metformin decreases hepatic glucose production and intestinal absorption of glucose and improve the insulin sensitivity. In PCOS, metformin reduces fasting insulin, stimulating luteinizing hormone and free testosterone levels. ${ }^{9}$

A pregnant woman with PCOS is a high risk of miscarriage as well as baby deformities of limb and health problems which may increase the abortion rate has increased. PCOS is may cause irregular menstrual periods and diabetes which can be altered by metformin or insulin sanitizing agents. Metformin may improve reproduction abnormalities in women with PCOS by restoring ovulation, curing infertility, preventing pregnancy loss and reducing pregnancy complications. ${ }^{10}$

From our study we observed that metformin therapy is reducing the number of acne and hirsutism. Kelly et al., also studied the effect of metformin on PCOS and found that metformin had significant improvement in hirsutism at the end of metformin therapy. Metformin also reduced the body weight and improve the menstrual cycle frequency. ${ }^{11}$ Velazquex et al., observed that $27 \%$ of the study participants were resumed with normal measures and there become pregnant after metformin therapy. ${ }^{12}$

Women with PCOS had problem with the distressing prospect of a substantially increased risk of miscarriage during the first trimester, which need to be addressed by consulting and life style modification. Simultaneously, patient advised for drug therapy with metformin which will reduce the rate of miscarriage. Glueck et al reported that continuing metformin throughout pregnancy in women with PCOS is safety and reduces first trimester miscarriage from $64 \%$ to $5 \%$ without teratogenicity. ${ }^{5,13}$ Metformin administration may decrease the rate of early pregnancy loss by several potential mechanisms including elevated serum androgen concentration and improving insulin senitivity. ${ }^{2,14}$

\section{CONCLUSION}

Administration of metformin to pregnant women with PCOS throughout pregnancy was associated with a marked and significant reduction in the rate of early pregnancy loss. It also reduces hirsutism and acne in certain cases and improves the live birth rates.

\section{ACKNOWLEDGEMENT}

Authors are highly thankful to the physician, staffs, and medical record officers of Vaatsalya hospital, Mandya.

\section{CONFLICT OF INTEREST}

None

\section{ABBREVIATIONS USED}

PCOS: Polycystic ovary syndrome.

\section{REFERENCES}

1. Sirmans SM, Pate KA. Epidemiology, diagnosis, and management of polycystic ovary syndrome. Clin Epidemiol. 2013;6(12):1-13. https://doi.org/10.2147/CLEP. S37559 PMid:24379699 PMCid:PMC3872139.

2. Najmabadi S, Wilcox JG, Acacio BD, Thornton MH, Kolb BA, Paulson RJ. The significance of polycystic-appearing ovaries versus normal appearing ovaries in patients with polycystic ovary syndrome. Fertil Steril. 1997;67(4):631-5. https:// doi.org/10.1016/S0015-0282(97)81357-X

3. Goodarzi MO, Dumesic DA, Chazenbalk G, Azziz R. Polycystic ovary syndrome: etiology, pathogenesis and diagnosis. Nat Rev Endocrinol. 2011;7(4):219-31. https://doi.org/10.1038/nrendo.2010.217 PMid:21263450.

4. Homburg R. What is polycystic ovarian syndrome? A proposal for a consensus on the definition and diagnosis of polycystic ovarian syndrome. Hum Reprod. 2002;17(10):2495-9. https://doi.org/10.1093/humrep/17.10.2495 PMid:12351518.

5. Glueck CJ, Wang P, Fontaine R, Tracy T, Sieve-Smith L. Metformin to restore normal menses in oligo-amenorrheic teenage girls with polycystic ovary syndrome (PCOS). J Adolesc Health. 2001;29(3):160-9. https://doi.org/10.1016/ S1054-139X(01)00202-6.

6. Ben-Haroush A, Yogev Y, Fisch B. Insulin resistance and metformin in polycystic ovary syndrome. Eur J Obstet Gynecol Reprod Biol. 2004;115(2):125-33. https:// doi.org/10.1016/j.ejogrb.2003.11.027 PMid:15262344.

7. Nestler JE, Jakubowicz DJ, Evans WS, Pasquali R. Effects of metformin on spontaneous and clomiphene-induced ovulation in the polycystic ovary syndrome. N Engl J Med. 1998;338(26):1876-80. https://doi.org/10.1056/ NEJM199806253382603 PMid:9637806.

8. Zisser HC. Polycystic Ovary Syndrome and Pregnancy: Is Metformin the Magic Bullet? Diabetes Spectrum. 2007Apr;20(2):85-9.: Feig DS. Metformin Therapy During Pregnancy. Diabetes Care. 2011;34(10):2329-30. https://doi.org/10.2337/ dc11-1153 PMid:21949224 PMCid:PMC3177745.

9. Al-Biate MA. Effect of metformin on early pregnancy loss in women with polycystic ovary syndrome. Taiwan J Obstet Gynecol. 2015;54(3):266-9. https:// doi.org/10.1016/j.tjog.2013.06.020 PMid:26166338.

10. Legro RS. Metformin during pregnancy in polycystic ovary syndrome: another vitamin bites the dust. J Clin Endocrinol Metab. 2010;95(12):5199-202. https:// doi.org/10.1210/jc.2010-2301 PMid:21131540 PMCid:PMC2999976.

11. Kelly CJ, Gordon D. The effect of metformin on hirsutism in polycystic ovary syndrome. Eur J Endocrinol. 2002;147(2):217-21. https://doi.org/10.1530/ eje.0.1470217.

12. Velazquez EM, Mendoza S, Hamer T, Sosa F, Glueck CJ. Metformin therapy in polycystic ovary syndrome reduces hyperinsulinemia, insulin resistance, hyperandrogenemia, and systolic blood pressure, while facilitating norma menses and pregnancy. Metabolism. 1994;43(5):647-54. https://doi.org/10.1016/ 0026-0495(94)90209-7.

13. Glueck CJ, Phillips H, Cameron D, Sieve-Smith L, Wang P. Continuing metformin throughout pregnancy in women with polycystic ovary syndrome appears to safely reduce first-trimester spontaneous abortion: a pilot study. Fertil Steril. 2001;75(1):46-52. https://doi.org/10.1016/s0015-0282(00)01666-6.

14. Nothnagle M, Taylor JS. Does metformin improve clinical features of polycystic ovary syndrome?. Am Fam Physician. 2003;68(11):2163-4. PMid:14677661.

Article History: Submission Date: 23-11-16; Received Date: 29-11-16; Acceptance Date:28-12-16.

Cite this article: Mohan C, Vannan M, Ali A, Parasuraman S. Evaluation of Clinical Efficacy of Metformin Therapy in Polycystic Ovary Syndrome. J Young Pharm. 2017:9(2):277-9. 